\title{
Design Optimization Approach Based on Finite Element Analysis for Controller Control Cabinet of Explosion-proof Elevator
}

\author{
Ji'ai Xue, Weiping Ouyang", Yannan Du and Huiqing Ouyang \\ No. 915 Jinshajiang Road Shanghai, China \\ ${ }^{*}$ Corresponding author
}

\begin{abstract}
The influence of the size, structure and material of the frame on the explosion pressure is studied aiming at typical controller control cabinet. It is proved that the maximum stress value decreases with the increase of the thickness of the main chamber under blast pressure. The clearance value of the maximum joint surface increases with the decrease of the thickness of the main cavity, and the clearance of flange joint increases with the increase of connecting bolt spacing. To ensure explosion protection safety flameproof cabinet that has enough performance, the appropriate materials should be selected according to the mechanical properties and economy, weldability. The minimum thickness of the frame, the thickness of the cover and connecting bolt spacing should be limited based on the structure. The finite element calculation and analysis of the explosion-proof control cabinet can be used as an important part of the control cabinet design, which can provide technical support for the design, material selection and related technical specification for controller control cabinet of explosion-proof elevator.
\end{abstract}

Keywords-finite element analysis; explosion-proof elevator; design optimization approach

\section{INTRODUCTION}

Blast defense elevator is a complex set of electromechanical equipment working in explosive places, especially the explosion-proof performance is critical [1-2]. Blast defense control cabinet is an important aspect of explosion-proof elevator. The explosion-proof and intrinsically safety are the two most common types of explosion-proof control cabinet. Blast defense product is an explosion-proof product of strength type which can be used for the explosionproof of the power system. Blast defense product is an explosion-proof product of strength type, which is often used in the explosion - proof of strong electric system. The shell is in a position to withstand the internal explosion without any damage caused by the combustible mixture that penetrates any joint surface or structural clearance inside the shell [34].Intrinsically safety product is an explosion-proof product with energy security type, which can be used in the explosionproof of weak current system. The explosive gas environment cannot be ignited by any spark or thermal effect produced by the normal condition and specified fault condition [5-7].

Special explosion protection structure isn't required for the intrinsically safe explosion-proof cabinet. Therefore, there is no essential difference in the structure of the common controller. While, in order to obtain good explosion-proof effect, the structure of control cabinet needs special explosion design. Although the basic function and structure of explosion-proof control cabinet are very relatively simple, there is a big difference in the structure of the explosion control cabinet existing in the market due to the different design features. In this paper, a typical explosion-proof control cabinet of explosion-proof elevator is studied and the finite model of the explosion-proof control cabinet is established. The effect of the size, structure and material of explosion-proof frame on the maximum explosion pressure is studied. This can provide the technical support for the design of the control cabinet, material selection and related technical specification.

\section{FINITE ELEMENT MODEL}

In this paper, a typical explosion-proof control cabinet of explosion-proof elevator is studied and the finite model of the explosion-proof control cabinet is established. The characteristics of strength and rigidity are studied under the maximum explosive pressure. Then, the influence of the size, structure and the material on the explosion-proof property of the explosion-proof frame is discussed. The main chamber of the elevator control cabinet is an open cube space produced by five steel plates and a closed cube space is formed through the flange and cylinder connection in the opening side. The main chamber of the cabinet is composed of the steel plate, which has the characteristics of large strain and large deformation.

The shell 93 element suitable for the bending shell is selected when the finite element model of the control cabinet frame is built. The elasticity modulus of materials E is $206 \mathrm{Gpa}$, and poisson ratio $\mu$ is 0.3 considering the material of the control cabinet. In the actual control cabinet, the frame and case cover are connected by the blots and nuts. In order to realize the connection of thread in the finite element model, the bolt joint between the case cover and the flange is simulated by coupling nodal degrees. The number of coupled nodes is consistent with the number of the thread connections. The node coupling relationship in the finite model is given in Fig.1. Although the wall thickness of the explosion-proof elevator is larger than that of the ordinary elevator control cabinet, it is still far less than the overall size of the control cabinet. Therefore, the shell element is chosen in the finite model of the 
control cabinet. It could ensure the calculation accuracy and save the computation time compared with the solid modeling.

The parameters of the control cabinet are shown in Table.1, whose material is Q235. The connecting bolt specification is $\mathrm{M} 12 \times 40$.The actual control cabinet is usually placed on the ground and the main chamber of the control cabinet is part of the control cabinet. Therefore, the displacement of the four corners of the control cabinet is constrained and the rotational degree of freedom is not taken into consideration. The explosion is carried out inside the main chamber of the cabinet and the impact of explosive pressure on the cabinet, and the box cover is basically the same. Therefore, the load applied at the control cabinet and cover should be pressured. The direction of the load is from the inside out and the pressure on the surface of the control cabinet and the cover is the same during the finite analysis. According to the GB3836.2-2000, the maximum pressure in the dynamic test explosion is $0.72 \mathrm{MPa}$ when the withstand pressure explosion-proof test of the control cabinet is performed. Therefore, this pressure value is selected as the load value.

\section{RESUlTS AND DisCUSSION}

\section{A. Effect of Surface Clearance}

The effect of the surface clearance between the cover and the flange is studied under the maximum explosion pressure. The clearance result of upper joint surface along the width direction of the main chamber is shown in Figure 2(a). It could be noted that the clearance of thread connection position is zero, which is consistent with the hypothesis that the connection. The clearance of upper joint surface along the width direction of the main chamber appears between two adjacent thread connection. The maximum value appears at the mid-point of the width, and the maximum value is about $0.014 \mathrm{~mm}$. The clearance of the right section of along the height direction of the control cabinet is illustrated in Figure 2(b). It could be found that the clearance of thread connection position is zero. The clearance of upper joint surface along the height direction of the main chamber appears between two adjacent thread connection, and the maximum value appears at the mid-point of the height, and the maximum value is about $0.0146 \mathrm{~mm}$.

TABLE I. PARAMETERS OF THE CONTROL CABINET

\begin{tabular}{|l|l|l|l|}
\hline $\begin{array}{l}\text { The cavity size of } \\
\text { the main chamber } \\
(\mathrm{mm})\end{array}$ & $365 \times 600 \times 822$ & $\begin{array}{l}\text { Width of Cover } \\
\text { Flange }(\mathrm{mm})\end{array}$ & 50 \\
\hline $\begin{array}{l}\text { Thickness of } \\
\text { frame steel plate } \\
(\mathrm{mm})\end{array}$ & 16 & $\begin{array}{l}\text { Thickness of } \\
\text { Cover Steel Plate } \\
(\mathrm{mm})\end{array}$ & 20 \\
\hline $\begin{array}{l}\text { Thickness of } \\
\text { frame flange } \\
(\mathrm{mm})\end{array}$ & 20 & $\begin{array}{l}\text { Distance of bolt } \\
\text { center. }(\mathrm{mm})\end{array}$ & 60 \\
\hline
\end{tabular}

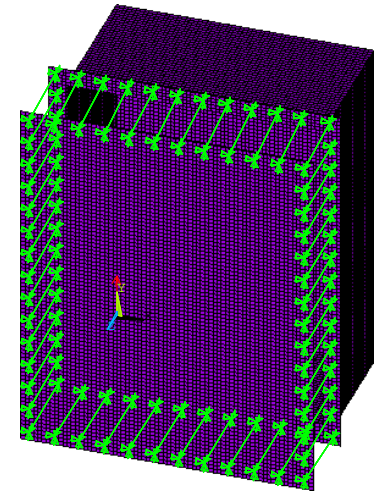

FIGURE I. REALIZATION OF THE BOLTED CONNECTION IN ANSYS
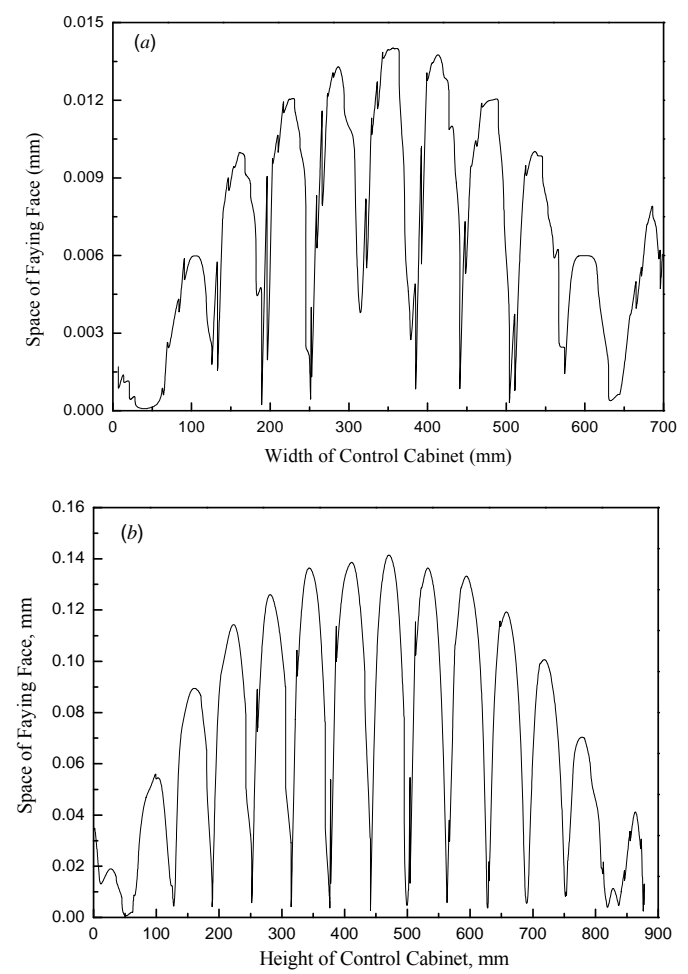

FIGURE II. REALIZATION OF THE BOLTED CONNECTION IN ANSYS

\section{B. Effect of the Thickness of Main Chamber}

The effect of the surface clearance between the cover and the flange is studied under the maximum explosion pressure. The clearance result of upper joint surface along the width direction of the main chamber 


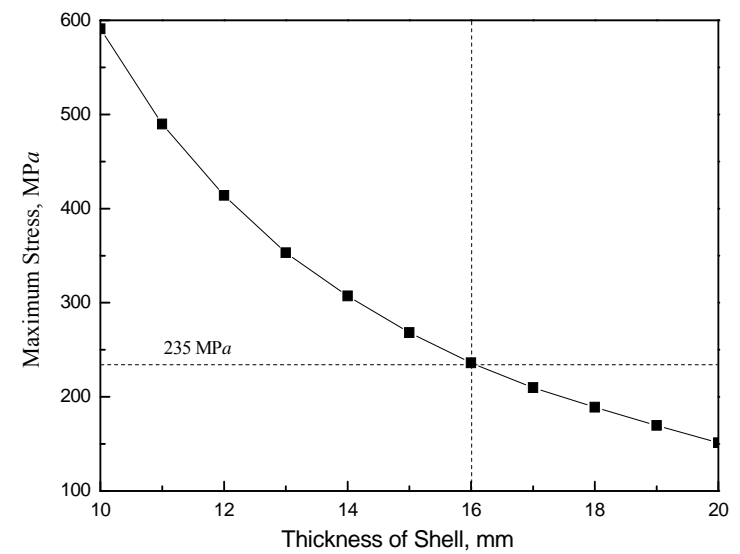

FIGURE III. RELATIONSHIP BETWEEN SHELL THICKNESS AND MAXIMUM STRESS

\section{Effect of Cover Equations Thickness}

The thickness of the cover of the main chamber of the cabinet is changed in the finite element model, and the other conditions remain unchanged and the calculation is made. Fig. 4 gives the relationship between the foremost chamber cover thickness and the joint surface clearance of the main chamber cover and the flange. The broken line in the figure represents the yield limit, which is the maximum detail permitted by GB3836.2 when the explosion protection level is IIC level. The thickness of the main chamber of the main chamber was decreased with the decrease of the thickness of the main chamber of the principal chamber under the explosion pressure. Only when the wall thickness of the cover of the main chamber is larger than $10 \mathrm{~mm}$, it could ensure the safety of the cabinet chamber.

\section{Selection of Main Chamber Material}

Due to the different mechanical properties of materials, different materials have different explosion-proof properties. The simulation is calculated according to the different materials. It is indicated the relationship between the minimum thickness and the material of the main chamber in Figure 5. As can be seen from Fig.5, if Q235 is selected, the wall thickness must be greater than $16 \mathrm{~mm}$. If $20 \mathrm{Cr}$ with higher yield strength is selected, the minimum thickness can be reduced to $10 \mathrm{~mm}$. Therefore, the material with higher yield strength or tensile strength could reduce the wall thickness of the main chamber.

It is important to note that the economic and welding properties of the materials are not considered in this section. The material with better mechanical properties can reduce the wall thickness of the box and reduce the mass. It will inevitably lead to higher costs, and welding performance may decline. Thus, not only the explosion-proof performance, but also combine many other factors should be considered comprehensively in the design process.

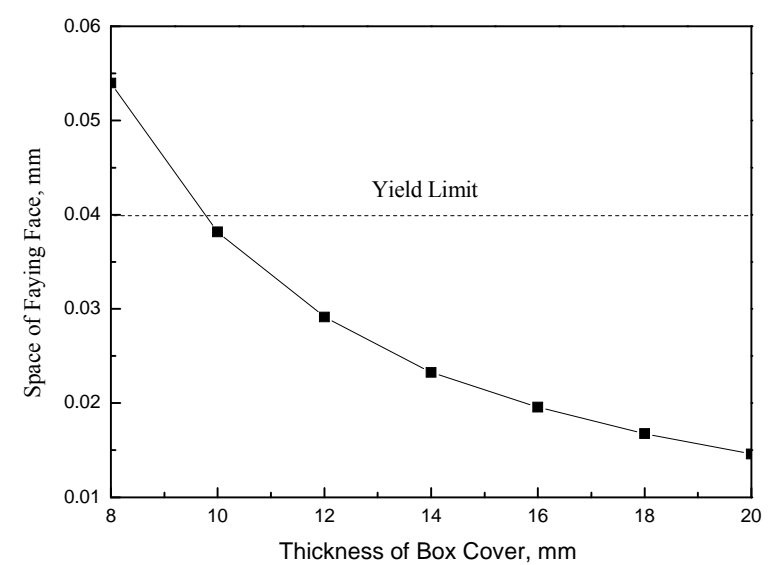

FIGURE IV. RELATIONSHIP BETWEEN THE THICKNESS OF THE COVER AND THE CLEARANCE OF THE JOINT SURFACE
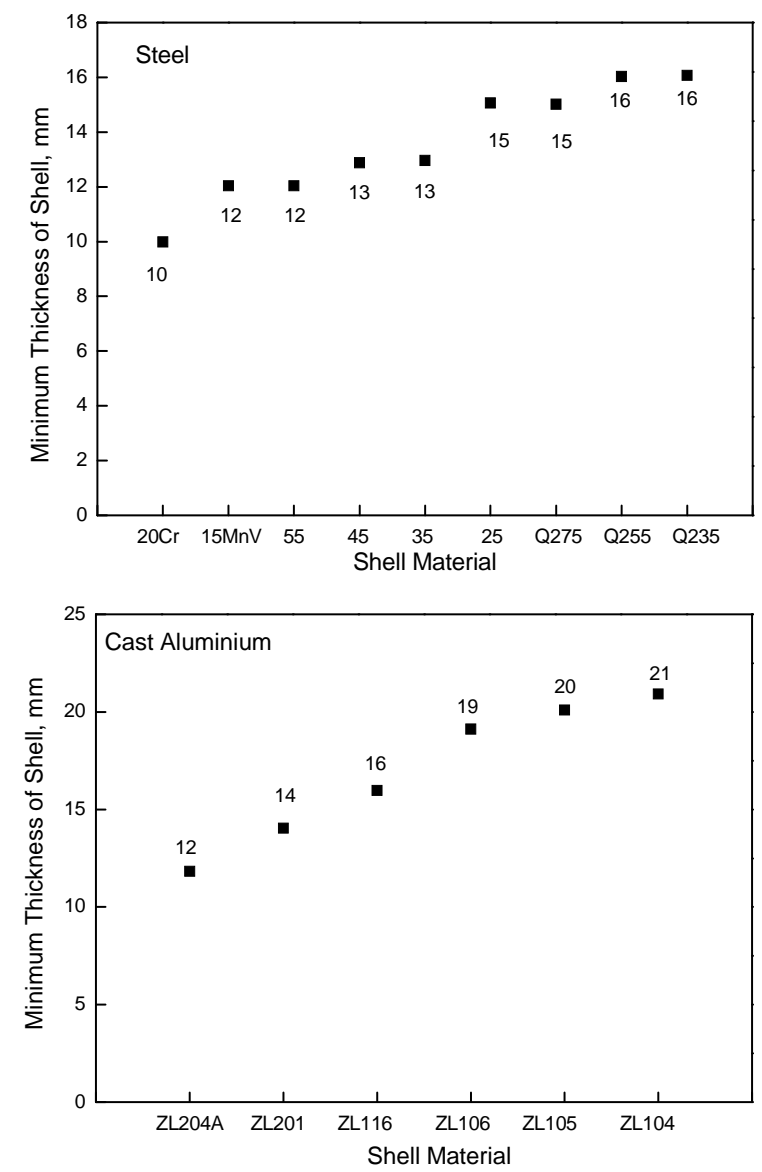

FIGURE V. RELATIONSHIP OF THE MINIMUM THICKNESS AND THE MATERIAL OF THE MAIN CHAMBER 


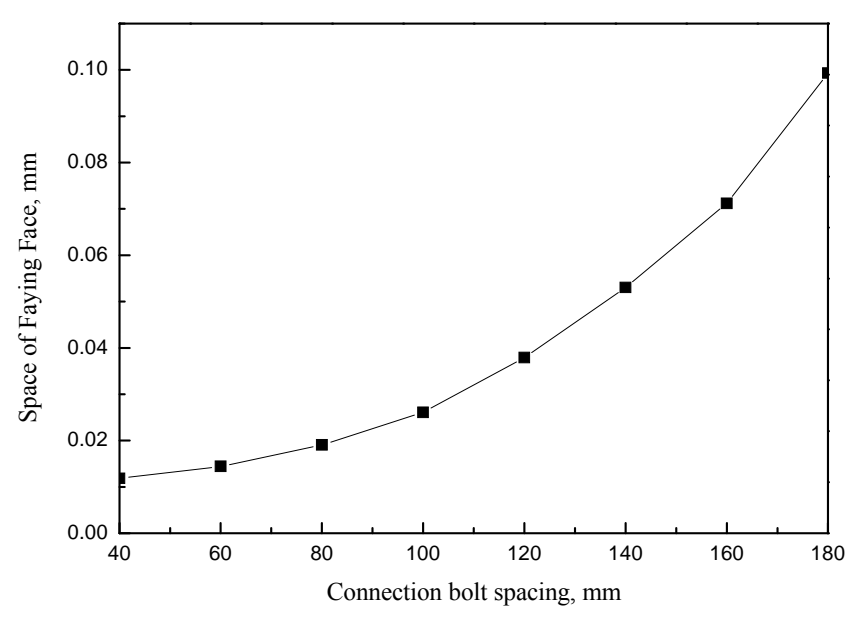

FIGURE VI. RELATIONSHIP BETWEEN THE CONNECTING BOLT SPACING AND JOINT SURFACE CLEARANCE

\section{E. Effect of Connecting Bolt Spacing}

Bolts are generally used to connect the cover of the flameproof control cabinet and the frame flange, referring to GB3836.2 standard. In ensuring the fastness and reliability of the threaded connection itself, the spacing between the two adjacent bolts may affect the joint surface between the cover and the flange shown as in the Fig.6. It can be found that under the maximum explosion pressure, the spacing between the connecting bolts is within the range of $40 \mathrm{~mm}-180 \mathrm{~mm}$, and the clearance of the joint surface increases with the increase of the spacing of the bolts. Thus, it is necessary to limit the spacing of connecting bolts while ensuring that the main chamber has sufficient explosion-proof safety performance.

\section{CONCLUSION}

(1) The finite element calculation and analysis of the explosion control cabinet could be used as an important part of the control cabinet design, which could optimize the structure design parameters of the cabinet.

(2) Under the predetermined load, the maximum stress value of the box decreases with the increase of the thickness of the main chamber. The clearance value of the maximum joint surface increases with the decrease of the thickness of the main cavity. The clearance of flange joint increases with the increase of connecting bolt spacing.

(3) To ensure explosion protection safety flameproof cabinet that has enough performance, the appropriate materials should be chosen according to the mechanical properties and economy, weldability. The minimum thickness of the frame, the thickness of the cover and connecting bolt spacing should be limited based on the structure.

\section{REFERENCES}

[1] Z. H. Jiang, J. Liang, Y.X. Zhang and X.H. Wang, "Explosion-proof performance inspection of explosion-proof elevator traction machine and control cabiner," China Special Equipment Safety, vol. 6, pp. 42-46, June 2015 .
[2] H. Zhou, F. Luo, F.Y. Luo and N. Y Wu, "Type test control system design of lift control cabinets," Mechanical \& Electrical Engineering Technology, vol. 7, pp. 85-86 136, September 2008.

[3] Z.H Jiang, J. Liang, Y.X. Zhang and X.H Wang, "Explosion-proof performance inspection of explosion-proof elevator traction machine and control cabinet," China Special Equipment Safety, vol. 6, pp. 42-46, June 2015.

[4] B.G. Yang, "Fault Detection Expert System of Elevator Control Cabinet Based on Labview," Applied Mechanics and Materials, vol. 539, pp. 596-600, july 2014.

[5] Q. P. Zhang, J.R Wan, "Numerical simulation and analysis of thermal energy generated by friction on explosion-proof elevator," Advanced Materials Research, vol. 853, pp. 421-427, December 2013.

[6] X.T. Li, J Zhang and X.L Zhang"Finite element static strength analysis of certain type ship control cabinet," Ordnance Industry Automation, vol. 9, pp. 94-96, November 2017.

[7] H.E Niu, C Feng, H.F. An, Q.Y. Hou and X. C Lu, "Finite element modal and experimental modal analysis of explosion-proof motor frame," Electric Explosion Protection, vol. 1, pp. 13-16, Janulry 2017. 